\title{
Histochemistry of mucin secreting components in mucoepidermoid and adenosquamous carcinoma of the oesophagus
}

\author{
K Y Lam, S L Loke, L T Ma
}

\begin{abstract}
Aims-To determine the direction of differentiation of the mucin secreting components in a rare group of oesophageal tumours-oesophageal squamous cell carcinomas with prominent mucin secreting components (mucoepidermoid carcinomas and adenosquamous carcinomas).

Methods-In a review of 617 cases of primary carcinoma of the oesophagus, 16 cases of squamous cell carcinoma with prominent mucin secreting components were studied using a battery of histochemical techniques.

Results-The mucin produced by these tumours was mixed and included a variable content of enzyme labile sialomucin (positive for mucicarmine, periodic acid Schiff, and alcian blue, and sensitive to sialidase digestion and negative for high iron diamine-alcian blue). Retrospective analysis of endoscopic biopsy specimens taken from these tumours showed that mucin was present in five (42\%) cases.

Conclusions-The glandular component of this group of tumours histochemically differentiated in the direction of oesophageal glands: examination of the mucin secreting component in squamous cell carcinoma in resected specimens is therefore required for recording the true incidence of this type of tumour.
\end{abstract}

(F Clin Pathol 1993;46:1011-1015)

Glandular or mucin secreting components in squamous cell carcinoma of oesophagus are rare.$^{1-20}$ In reviewing the published findings in earlier years, ${ }^{1-8}$ we found that it was rather difficult to establish the exact numbers of oesophageal mucus secreting squamous cell carcinomas for two reasons. First, some cases were actually gastric cancers with extension to the oesophagus. Theoretically, the confusion could be avoided in most cases by paying attention to the exact anatomical location of the tumour, the presence of carcinoma in situ changes in the oesophageal mucosa adjacent to the tumour (which suggest a primary esophageal origin), and histological type (as squamous cell carcinoma is unlikely to arise from the stomach). The second reason lies in the use of different terminology for describing similar histological patterns. Different terms - collision tumour, adenoacanthoma, adenocarcinoma with squamous metaplasia, mixed squamous and glandular carcinoma, mucoepidermoid carcinoma, adenosquamous carcinoma-have been used. To avoid the confusion created by these inconsistencies, we labelled this group of tumours squamous cell carcinoma with mucin secreting components (which includes tumours classified either as adenosquamous or mucoepidermoid carcinoma in the WHO classification).

It has been suggested that these carcinomas originate from the oesophageal mucus glands or ductal epithelium..$^{9}$ This study was undertaken to explore this view by examining the nature of the mucin produced by these tumours.

\section{Methods}

The records of patients with primary oesophageal carcinoma who had undergone resection in the surgical units of Queen Mary Hospital between 1981 and 1992 were reviewed. Eighty one per cent of the operations had been carried out by the same team of surgeons and we reported the pathological features (by consensus between two of the three pathologists, Ma, Loke, and Lam). Multiple blocks (at least one block from each tumour $1 \mathrm{~cm}$ in diameter) were taken from every oesophageal tumour for microscopic examination during routine examination. The sections from tumours with a squamous carcinomatous component and evidence of mucin secretion were reviewed. Careful histological examination of the mucin secreting component was carried out to exclude cases in which the mucin component was related to the encasement of normal oesophageal glands by squamous cell carcinoma. Because there are no definitive criteria for the amount of mucin required for either the diagnosis of mucoepidermoid carcinoma or adenosquamous cell carcinoma, we chose cases in which the mucin secreting component comprised at least $10 \%$ of the tumour (identified even without the use of mucin stains) for further study. This excluded cases with focal mucin production (often seen in squamous cell carcinoma in other parts of the body) and allowed better and easier interpretation of the pathological features, including mucin staining properties.

Cases of pure adenocarcinoma (without squamous differentiation) and adenoid cystic carcinoma were excluded from the study. Carcinomas arising from the cardia were separated out from those affecting the lower oesophagus by paying attention to the exact 
Table 1 Staining properties of different types of mucin

\begin{tabular}{llllll}
\hline Type & Location & $P A S$ & $A B$ & $H D$ & Sialidase \\
\hline $\begin{array}{l}\text { Neutral mucin } \\
\text { Acid mucin }\end{array}$ & Stomach & + & - & - & Resistant \\
$\begin{array}{l}\text { Sialomucin:enzyme-labile } \\
\text { Sulphomucin }\end{array}$ & $\begin{array}{l}\text { Salivary gland } \\
\text { Intestinal metaplasia }\end{array}$ & \pm & + & - & Sensitive \\
\hline
\end{tabular}

PAS, periodic acid Schiff; AB, alcian blue ( $\mathrm{pH} \mathrm{2.5);} \mathrm{HID,} \mathrm{high} \mathrm{iron} \mathrm{diamine.}$

anatomical site, histological type (as squamous cell carcinomas are unlikely to arise from the cardia), and the presence of carcinoma in situ changes in the oesophagus (absent in carcinomas arising from the cardia). Barrett's epithelium in adjacent mucosa was searched for in every tumour.

The clinical features of these tumours were examined and compared with those of pure squamous cell carcinoma. The pathological features, such as the differentiation of the squamous component, were also examined. Tumours with prominent keratin pearls, intercellular bridges, and cell layers in the squamous carcinomatous component undergoing differentiation were counted as well differentiated; tumours with little or no keratin, intercellular bridges, and differentiation of cell layers were classified as poorly differentiated, and those with intermediate features were classified as moderately differentiated. The mucin secreting component was analysed for the presence of a tubular glandular component and degree of mixing with the squamous carcinomatous component.

Representative blocks from these tumours were chosen for histochemical studies. Sequential microscopic sections were made and stained with mucicarmine (MC), high iron diamine-alcian blue, $\mathrm{pH} 2.5$ (HID-AB), alcian blue (pH 2.5)periodic acid Schiff (ABPAS) with and without sialidase digestion. The staining characteristics of these histochemical stains are shown in table 1 . Mucicarmine was used as a preliminary screen for mucin; AB-PAS was used to detect mucoid substances and to differentiate between neutral (magenta) and acid (blue) substances. The latter were further classified into sialomucin (negative, blue) and sulphomucin (positive, brown) by HID-AB. Sialidase digestion on AB-PAS stained sec- tions was used to detect the enzyme labile type of sialomucin. More magenta in colour than before treatment indicated sensitivity. The susceptibility to sialidase was compared with the adjacent normal oesophageal glands in the same section which acted as an internal control. The previous endoscopic biopsy specimens taken from the tumours were also retrieved and stained with mucicarmine. All the sections were then assessed independently and with consensus among the authors.

\section{Results}

Of a total of 617 cases of resected primary oesophageal carcinoma, $600(97 \cdot 3 \%)$ were carcinomas with a pure or predominant squamous component. The remaining cases included six $(1 \%)$ small cell carcinomas, two $(0.3 \%)$ adenocarcinomas, two adenocytic carcinomas $(0.3 \%)$ and seven $(1 \cdot 1 \%)$ undifferentiated carcinomas. Forty out of the 600 $(6 \cdot 7 \%)$ cases with a squamous carcinomatous component showed the presence of mucinsecreting components. Of these, 16 cases with a prominent mucin component were selected for further analysis. The clinical characteristics of these tumours were similar to those of squamous cell carcinoma, as reported recently by our group. ${ }^{21}$ The age of the patients with these tumours ranged from 50 to 91 years, with a mean of 66 years. The male to female ratio was $7: 1$. The middle third of the oesophagus was the most common primary site of these group of tumours. The upper third was the site in four $(25 \%)$ cases, the middle in eight $(50 \%)$ cases, and the lower third in four (25\%) cases (table 2).

The squamous carcinomatous component was the major component in all cases $(50 \%$ to $90 \%$ of the epithelial part of the tumour). The tumour was poorly differentiated in 10 cases, moderately differentiated in five, and well differentiated in one case. The predominant histological pattern showed distinct tubular mucin-secreting components (adenosquamous carcinoma) (fig 1) in four cases (cases 4, 12, 14 and 16) and was admixed with the squamous carcinomatous components in the other cases (mucoepidermoid carcinoma) (fig 2). Barrett's epithelium was not present in all cases.

Table 2 Histochemical properties of mucin secreting oesophageol squamous cell carcinomas

\begin{tabular}{|c|c|c|c|c|c|c|c|c|}
\hline \multirow[b]{2}{*}{ Case No } & \multirow[b]{2}{*}{ SLX/Age } & \multirow[b]{2}{*}{$M C$} & \multirow[b]{2}{*}{$P A S$} & \multirow[b]{2}{*}{$A B$} & \multirow[b]{2}{*}{ Sialidase } & \multicolumn{3}{|c|}{ Previous biopsy specimen } \\
\hline & & & & & & $H I D$ & Diagnosis & $M C$ \\
\hline $\begin{array}{l}1 \\
2 \\
3 \\
4 \\
5 \\
6 \\
7 \\
8 \\
9 \\
10 \\
11 \\
12 \\
13 \\
14 \\
15 \\
16\end{array}$ & $\begin{array}{l}M / 77 \\
M / 55 \\
M / 58 \\
M / 57 \\
M / 79 \\
M / 58 \\
M / 70 \\
M / 64 \\
M / 61 \\
M / 50 \\
M / 63 \\
F / 91 \\
M / 63 \\
F / 79 \\
M / 61 \\
M / 65\end{array}$ & $\begin{array}{l}+ \\
+ \\
+ \\
+ \\
+ \\
+ \\
+ \\
+ \\
+ \\
+ \\
+ \\
+ \\
+ \\
+ \\
+ \\
+\end{array}$ & $\begin{array}{l}+ \\
+ \\
+ \\
+ \\
+ \\
+ \\
+ \\
+ \\
+ \\
+ \\
+ \\
+ \\
+ \\
+ \\
+ \\
+\end{array}$ & $\left.\begin{array}{l}+ \\
+ \\
+ \\
+ \\
+ \\
+ \\
+ \\
+ \\
+ \\
+ \\
+ \\
+ \\
+ \\
+ \\
+ \\
+\end{array}\right\}$ & sensitive & $\begin{array}{l} \pm \\
\pm \\
- \\
\pm \\
\pm \\
\pm \\
\pm \\
\pm \\
\pm \\
\pm \\
\pm \\
\pm \\
\pm \\
\pm \\
\pm \\
\pm\end{array}$ & $\begin{array}{l}\text { Squamous cell } \\
\text { Squamous cell } \\
\text { Undifferentiated } \\
\text { No previous biops } \\
\text { Squamous cell } \\
\text { Adenocarcinoma } \\
\text { Squamous cell } \\
\text { Squamous cell } \\
\text { No previous biops } \\
\text { Squamous cell } \\
\text { Squamous cell } \\
\text { Squamous cell } \\
\text { Squamous cell } \\
\text { No previous biops } \\
\text { Squamous cell } \\
\text { No previous biops }\end{array}$ & $\begin{array}{c}- \\
+ \\
\overline{-} \\
\text { lable } \\
+ \\
+ \\
+ \\
\text { lable } \\
+ \\
- \\
- \\
- \\
\text { lable } \\
\text { lable }\end{array}$ \\
\hline
\end{tabular}

HID staining: $+=$ black, $-=$ blue, $\pm=$ mixture, $\mathrm{MC}=$ mucicarmine. 


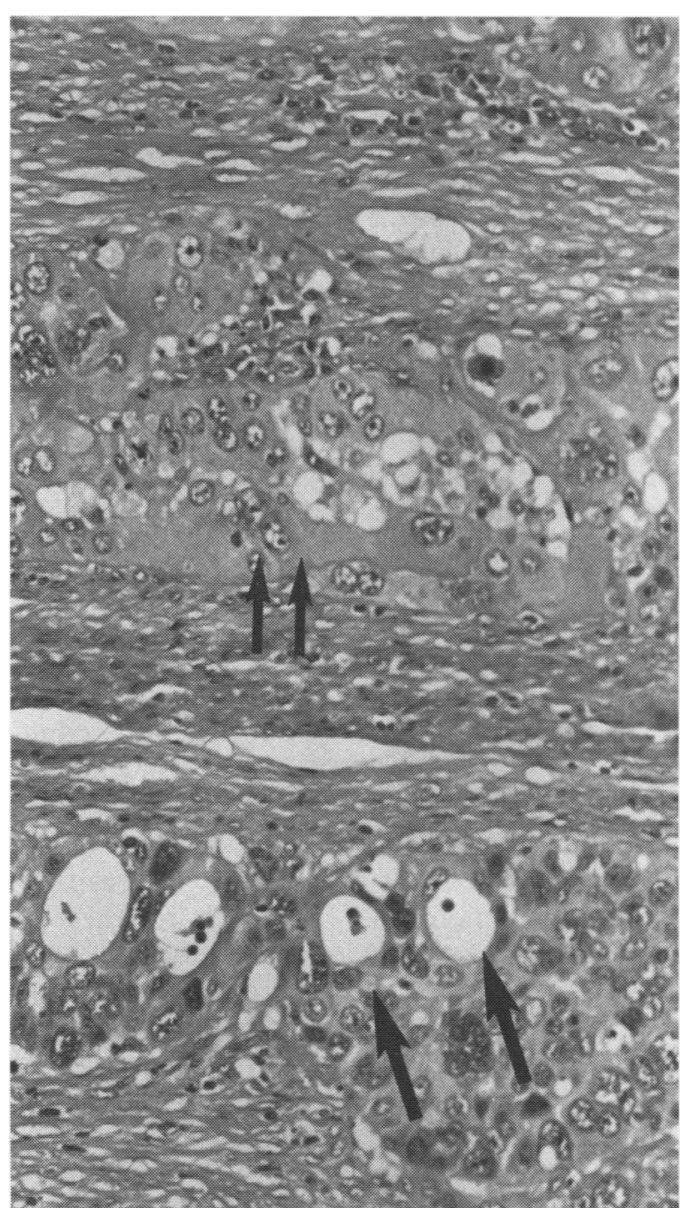

Figure 1 Oesophageal squamous cell carcinoma with mucin-secreting component in which the predominant pattern of tubular glandular elements (large arrows) was clearly demarcated from the squamous elements (small arrows) (haematoxylin and eosin).

Figure 3 Oesophageal squamous cell carcinoma with mucin-secreting component in which mucin component shows a mixture of mucin (arrows) (periodic acid Schiff and alcian blue).

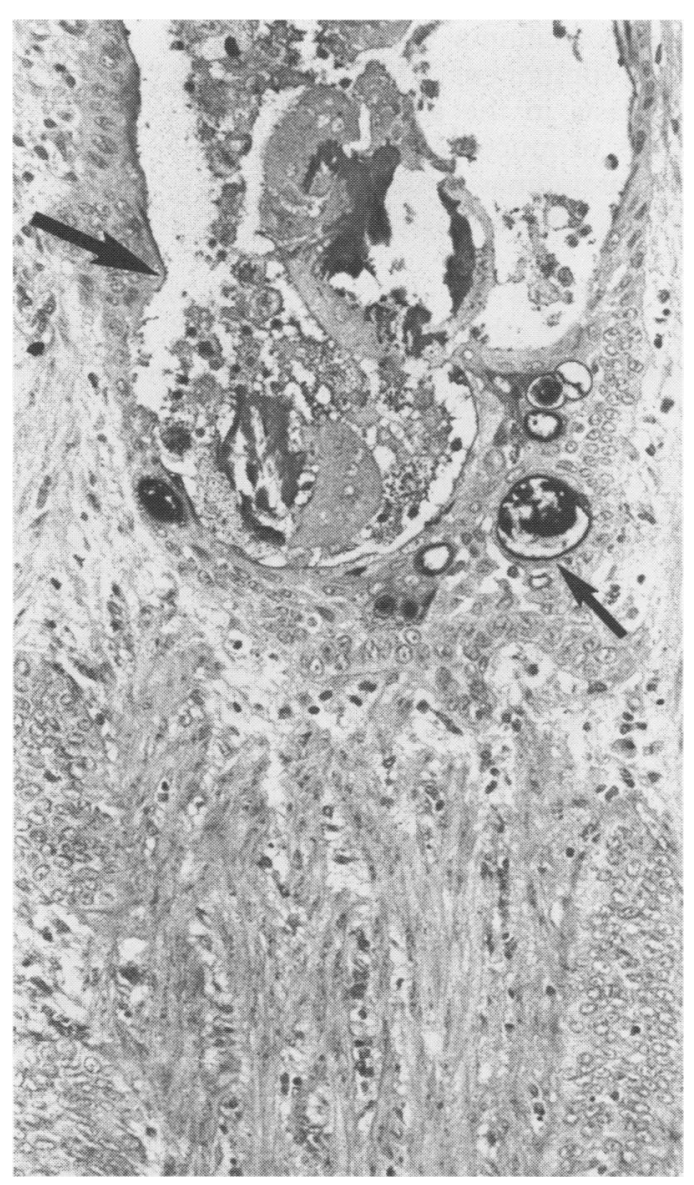

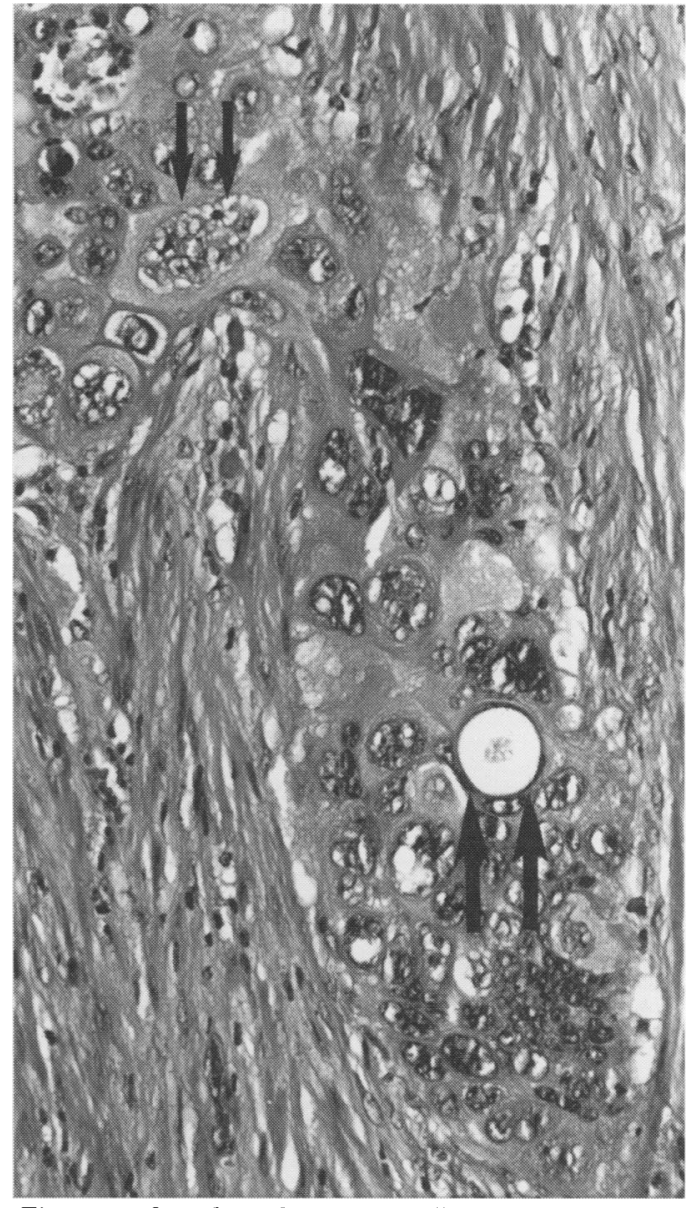

Figure 2 Oesophageal squamous cell carcinoma with mucin-secreting component in which predominant pattern of glandular (large arrows) and squamous component (small arrows) intermixed (haematoxylin and eosin).

A mixture of mucin, including enzymelabile sialomucin, was demonstrated in these oesophageal tumours (fig 3). All of the 16 tumours were positive for mucicarmine, PAS, and $A B$ but they showed various degrees of susceptibility to sialidase digestion. Two cases were HID negative and 14 showed a mixture of positive and negative reactions to HID staining. An increase in acidic mucin, mostly sialomucin, was noted in the mucin components of these tumours when compared with the adjacent. oesophageal glands.

Twelve of these tumours had positive endoscopic biopsy specimens available for reassessment and re-staining with mucin stain. Retrospective analysis showed that only five out of these $12(42 \%)$ cases were positive for mucicarmine staining. Ten cases were originally diagnosed as squamous cell carcinoma, one as adenocarcinoma, and one as undifferentiated carcinoma. The mucin component could not be easily identified in all the biopsy specimens taken earlier.

\section{Discussion}

Oesophageal tumours with both squamous and mucin secreting components are very rare. ${ }^{1-20}$ According to the recent edition of the WHO classification of tumours of the oesophagus, ${ }^{22}$ these tumours are classified either as adenosquamous carcinoma or 
mucoepidermoid carcinoma. Adenosquamous carcinoma is a tumour in which adenocarcinomatous and squamous carcinomatous components are intermingled or have a fairly clear boundary. The adenocarcinomatous component is usually tubular. On the other hand, mucoepidermoid carcinoma is characterised by the presence of an intimate mixture of squamous cells, mucus secreting cells, and cells of an intermediate type in varying proportions. Using these criteria as the predominant histological pattern for the tumours in this study, $75 \%$ (12 cases) could be classified as mucoepidermoid carcinomas and $25 \%$ (four cases) as adenosquamous carcinoma. Most of these tumours were not easily classified into distinct categories, however, because features of both mucoepidermoid carcinomas and adenosquamous carcinomas were present. This probably explains the reported variation in incidence as the boundary between these two histological types is not clearcut. All the oesophageal tumours in the present study were also shown to contain sialomucin. This similarity in histochemical and histological features does not warrant differentiation into two groups of tumours and they should be analysed together.

Adenocarcinoma of the oesophagus is common in the West, and Barrett's associated adenocarcinoma is increasing in incidence, ${ }^{23}$ but this is not the case in Hong Kong Chinese people. Over the study period, only two cases of primary oesophageal adenocarcinoma were found. This is at least partly a consequence of the rarity of Barrett's metaplasia and reflux disease in Asians. ${ }^{21}$ These cases were excluded from the study because they represented pure adenocarcinoma with no squamous carcinomatous component. The absence of Barrett's metaplasia in the adjacent mucosa in all the cases of mucoepidermoid and adenosquamous carcinomas in this study suggests that they are not associated with Barrett's metaplasia.

The origin of these tumours is still obscure. Most authors believe that this type of tumour arises from the oesophageal glands. ${ }^{9121315-17}$ Evidence in support of the theory includes the submucosal location of some of these tumours and the embryologically similar origin of the oesophageal and salivary glands. There are features that hint at a squamous epithelial cell origin for this group of tumours. First the behaviour of these tumours differs from that of mucoepidermoid carcinoma of salivary gland with similar histological features. Many of these tumours also show carcinoma in situ changes in the mucosa adjacent to the tumours. All these features suggest that these tumours arise from metaplastic changes in squamous epithelium..$^{18} 19$

Enzyme labile (sialidase sensitive) sialomucin is principally epithelial in origin. It has a wide distribution, either alone, or more commonly as a mixture with other types of mucin and is located in the submandibular salivary glands. ${ }^{24}$ It can be distinguished from other mucins by the positive reaction to alcian blue and PAS, sensitivity to sialidase digestion, and negativity for high iron diamine staining. In this study all the tumours contained sialomucin. Compared with the adjacent oesophageal gland, acidic mucin, mostly sialomucin, was increased. The mucin produced by these oesophageal tumours was histochemically similar, therefore, to that produced by the oesophageal glands (which contain enzyme labile sialomucin) rather than the gastric glands (which contain neutral mucin). The results suggest that the mucin secreting components of these tumours, histogenetically, have more in common with oesophageal glands than gastric mucosa. They may be either differentiated directly from multipotential stem cells in the oesophagus or from metaplastic changes in squamous cell carcinomas. Although intestinal type glands could also contain substantial amounts of enzyme labile sialomucin, the possibility that intestinal metaplasia could occur before neoplastic transformation is unlikely, because intestinal metaplasia adjacent to these tumours, has not been reported before.

The mucin component was noted in the initial biopsy specimen in only one case (case 6 , reported initially as adenocarcinoma in the first biopsy specimen). Retrospective analysis of these cases showed that mucin was present in five $(42 \%)$ cases so that the correct diagnosis in $58 \%$ of these tumours could not be made on the biopsy specimen taken during endoscopic examination.

Careful examination of oesophagectomy specimens is important for recognising the true incidence of this group of tumours.

We thank the staff of the Department of Surgery, Queen Mary Hospital, for the oesophagectomy specimens used in the study

1 Mallory TB. Cabot Case 21521. N Engl f Med 1935;213: 1311-15.

2 McPeak E, Arons WL. Adenoacanthoma of the oesophagus: a report of one case with consideration of tumor's resemblance to so-called salivary gland tumor. $A r c h$ Pathol 1947;44:385-90.

3 Gregg JB, Stamler FW. Unusual neoplasms of the esophagus. Arch Otolaryngol 1954;59:159-69.

4 Stout AP, Lattes R. Tumors of the esophagus. In: Atlas of Tumor Pathology, Section V, Fascicle 20. Washington, Dumor Pathology, Section V, Fascicle 20. Wash

5 Dodge OG. Gastro-oesophageal carcinoma of mixed histological type. ₹ Pathol Bacteriol 1961;81:459-71.

6 Azzopardi JG, Menzies T. Primary oesophageal adenocarcinoma: confirmation of its existence by the finding of mucous gland tumours. Br F Surg 1962;49:497-506.

7 Raven RW. Rare tumours of the pharynx and esophagus. Ann NY Acad Sci 1964;114:1061-79.

8 Raphael HA, Ellis FH, Dockerty MB. Primary adenocarcinoma of the oesophagus: 18-year review and review of literature. Ann Surg 1966;164:785-96.

9 Kuwano H, Ueo H, Sugimachi K, Inokuchi $K$ Toyoshima S, Enjoji M. Glandular or mucus-secreting components in squamous cell carcinoma of the esophagus. Cancer 1985;56:514-18.

10 Emoto I, Chihara T, Tamai $\dot{M}$, et al. A patient with double carcinoma of the esophagus-squamous cell carcinoma and mucoepidermoid carcinoma. $尹$ pn $¥$ Cancer Clin 1982;28:1754-7.

11 Matsufuji $\mathbf{H}$, Kuwano $H$, Ueo $H$, Sugimachi $\mathrm{K}$, Inokuchi K. Mucoepidermoid carcinoma of the oesophagus: a K. Mucoepidermoid carcinoma of

12 Woodard BH, Shelburne JD, Vollmer RT, Postlethwait RW. Mucoepidermoid carcinoma of the esophagus: a case report. Hum Pathol 1978;9:352-4.

13 Kay S. Mucoepidermoid carcinoma of the esophagus: report of two cases. Cancer 1968;22:1053-9. 
14 Bell-Thomson J, Haggitt RC, Ellis Jr FH. Mucoepidermoid and adenoid cystic carcinomas of the
oesophagus. $f$ Thoracic Cardiovasc Surg 1980;79: 438-46.

15 Osamura RY, Sato S, Miwa M, Miwa T Mucoepidermoid carcinoma of the esophagus: report of an unoperated autopsy case and review of literature. $\mathrm{Am}$ $\mathcal{f}$ Gastroenterol 1978;69:467-70.

16 Weitzner S, Albuquerque NM. Mucoepidermoid carcinoma of esophagus: report of a case. Arch Pathol 1970;90:271-3

17 Kuwano H, Sugimachi K, Morita M. A consideration of the definition of early oesophageal cancer on the basis of clinicopatholof viewpoint. Nippon Geka Gakkai Zasshi 1991;92:276-80.

18 Mafune $\mathrm{K}$. Histochemical study of adenocarcinomatous components in carcinoma of the esophagus. Nippon components in carcinoma of the
Geka Gakkai Zasshi 1988;89:162-72.

19 Pascal RR, Clearfield HR. Mucoepidermoid (adenosqua- mous) carcinoma arising in Barrett's esophagus. Dig Dis Sci 1987;32:428-32.

20 Sasajima K, Watanabe M, Tukabo K, Takai A, Yamashita K, Onda M. Mucoepidermoid carcinoma of the esophagus: report of two cases and review of the literature. Endoscopy 1990;22:140-3.

21 Law SYK, Fok M, Lam KY, Loke SL, Ma L, Wong J. Squamous cell carcinoma of the esophagus with mucinsecreting component (mucoepidermoid carcinoma) f Thoracic Cardiovasc Surg (in press)

22 Watanabe H, Jass JR, Sobin LH. Histological classification of oesophageal tumours. In: Histological typing of oesophageal and gastric tumours. 2nd edn. Heidelberg: Springer-Verlag, 1990:13.

23 Haggitt RC. Adenocarcinoma in Barrett's esophagus: a new epidemic? Hum Pathol 1992;23:475-6.

24 Cook HC. Carbohydrates. In: Bancroft JD, Stevens A, eds. Theory and practice of histological techniques. Edinburgh: Churchill Livingstone, 1990: 177-213. 